\title{
Pendidikan Keuangan Keluarga, Kesadaran Keuangan dan Tingkat Personal Finance
}

\section{Reza Widhar Pahlevi ${ }^{1}$ Dan Lazzuardi Nashrullah²}

${ }^{1}$ Fakultas Ekonomi Dan Sosial Universitas Amikom Yogyakarta

Jl. Ring Road Utara, Condong Catur, Yogyakarta. 55283, Indonesia

2Prodi Manajemen Fakultas Ekonomi Universitas Cokroaminoto Yogyakarta

Gambiran Umbulharjo, Yogyakarta, 55161, Indonesia

\section{Info Artikel}

\section{Keywords:}

Financial Awareness; Financial Education; Financial Literacy; and Personal Finance
Kata Kunci:

Kesadaran Keuangan; Literasi Keuangan; Pendidikan Keuangan dan Personal Finance

ISSN (print): 2598-7763 ISSN (online): 2598-7771

$\triangle$ Corresponding Author: Reza Widhar Pahlevi: Tel. /Fax.

E-mail:

rezawp@amikom.ac.id

\section{Abtract}

The purpose of this study was to determine the effect of financial education on the family, financial education on campus, peers, financial literacy and financial awareness on the level of student personal finance. The sampling technique uses a non probability sampling technique. While the sampling method uses incidental sampling, whoever by chance or fits as a data source, then continues using the purposive sampling method, namely the sampling technique with the consideration of students of the Faculty of Economics in Yogyakarta who have taken Financial Management courses and who have taken courses that concentrate on Finance. From these considerations, 103 respondents. The data analysis technique uses multiple regression analysis. The results showed that financial education in the family, financial literacy and financial awareness had a significant effect on student personal finance, while financial education on campus and peers had no effect on student personal finance.

Citation: Pahlevi, R.W. dan Nashrullah, L. (2020). Pendidikan Keuangan Keluarga, Kesadaran Keuangan dan Tingkat Personal Finance. AFRE Accounting and Financial Review. 3(2): 172-179

\section{Abstraks}

Tujuan penelitian ini adalah untuk mengetahui pengaruh pendidikan keuangan di keluarga, pendidikan keuangan di kampus, teman sebaya, literasi keuangan dan kesadaran keuangan terhadap tingkat personal finance mahasiswa. Teknik pengambilan sampel menggunakan teknik non probability sampling. Sedangkan metode pengambilan sampel menggunakan sampling incidental yaitu teknik penentuan sampel berdasarkan kebetulan, siapa saja yang secara kebetulanatau cocok sebagai sumberdata, kemudian dilanjutkan menggunakan metode purposive sampling yaitu teknik penentuan sampel dengan pertimbangan Mahasiswa Fakultas Ekonomi di Yogyakarta yang pernah mengambil mata kuliah ManajemenKeuangan dan yang pernahmengambil mata kuliah yang berkonsentrasi Keuangan. Dari pertimbangan-pertimbangan tersebut diperoleh 103 responden. Teknik analisis digunakan analisis regresi berganda. Hasil penelitian menunjukkan bahwa pendidikan keuangan di keluarga, literasi keuangan dan kesadaran keuangan berpengaruh signifikan terhadap personal finance mahasiswa sedangkan pendidikan keuangan di kampus dan teman sebaya tidak berpengaruh terhadap personal finance mahasiswa.

JEL Classification: G21; G53

DOI: $h$ ttps://doi.org/10.26905/afr.v3i2.5451 


\section{PENDAHULUAN}

Kemampuan mengelola uang (money management) merupakan hal yang cukup penting untuk dimiliki olehsetiap individu. Kesalahan dalam pengelolaan keuangan dapat berakibat pada kesuilitan keuangan (Hidayat, 2020; Pradiningtyas \& Lukiastuti, 2019; Ergün, 2018 Yushita, 2017; dan Idris et al., 2013). Saat ini masih cukup banyak masalah finansial yang tejadi disekitar kita. Hal tersebut mungkin saja terjadi karena kurangnya kesadaran dalam pengelolaan keuangan (money management). Setiap individu harus menyadari betapa pentingnya pengelolaan keuangan pribadi (personal finance), dengan kemampuan pengelolaan keuangan yang baik padasetiap individu maka masalah-masalah keuangan dapat teratasi dengan baik, dan rencana keuangan pun dapat terealisasi dengan baik.

Banyak faktor yang mempengaruhi kemampuan pengelolaan keuangan pribadi (personal finance) (Pathirannahalage \& Abeyrathna, 2020; Chuah et al., 2020; Ramadhan \& Asandimitra, 2019; Pahlevi \& Oktaviani, 2018; Isomidinova et al., 2017; Herdjiono \& Damanik, 2016; Gunay et al., 2015; dan Ahmad et al., 2014). Pendidikan keuangan di keluarga akan mempengaruhi prerilaku pengelolaan keuangan secara pribadi (Personal Finance) adalah pendidikan keuangan di keluarga. Pendi-dikan keuangan keluarga memungkinkan kita untuk dapat merencanakan dan mempersiapkan keuangan di masa sekarang dan masa depan. Hal ini terjadi sesuai dengan teori belajar sosial dimana seseorang belajar dengan meniru peristiwa yang ada dilingkungan keluarga mereka. Sehingga dalam lingkungan keluarga mahasiswa juga dapat melakukan proses belajar. Menurut Melmusi (2017) menyatakan bahwa keluarga yang telah melakukan pendidikan keuangan keluarga adalah orangtua yang telah mengajarkan nilai uang, menunjukan keteladanan yang baik dalam mengelola uang, mengajarkan dan melatih untuk rajin mena-bung, membiarkan anak dalam melakukan pembayaran sendiri atas kebutuhan tambahan dan mengelola uang saku, serta memiliki intesitas dalam mengelola keuangan anak. Hasil penelitian yang dilakukan oleh Syuliswati (2020), Goyal \& Kumar, 2020, Ameliawati \& Setiyani (2018); Amagir et al. (2018); Johnson \& Sherraden (2007) menunjukkan pendidikan keuangan keluarga ber-pengaruh positif terhadap pengelolaan keuangan pribadi.

Pendidikan keuangan seseorang di sekolah maupun di kampus akan mempengaruhi perilaku seseorang dalam mengelola keuangan. Pembelajaran di lingkungan Pendidikan, termasuk di perguruan tinggi juga memiliki peran yang cukup penting dalam proses pembentukan literasi keuangan mahasiswa. Mahasiswa tinggal di lingkungan ekonomi yang beragam dan kompleks sehingga peningkatan kebutuhan pendidikan keuangan sangat diperlukan. Pembelajaran di perguruan tinggi ini sangat berperan penting dalam proses pembentukan literasi finansial mahasiswa (Fatimah \& Susanti, 2018; Malinda, 2017; Erawati \& Susanti, 2016). Menurut Sari (2015) pembelajaran keuangan di perguruan tinggi sebagai sarana penting bagi sumbangan pengetahuan literasi mahasiswa. Pembelajaran pada perguruan tinggi mengenai keuangan memberikan impact bagaimana mahasiswa menggunakan dana, mempertimbangkan belanja, serta dalam melakukan keputusan keuangan lainnya.

Faktor teman sebaya juga akan mempengaruhi manajemen keuangan pribadi (Personal Finance). Teman sebaya dikatakan sebagai hubungan sosial yang terbentuk karena adanya tujuan pencarian jati diri yang dilakukan oleh dua orang atau lebih yang memiliki usia yang setara, serta kematangan yang sama, dimana mereka saling mengenal identitas sosial satu sama lain dan dapat mempengaruhi satu sama lain. Lingkungan pergaulan dapat berpengaruh pada karakteristik individu yang ada didalamnya, tak terkecuali juga karakteristik individu dalam mengelola keuangannya.

Financial literacy menjadi bagian penting yang mempengaruhi manajemen keuangan pribadi (Personal Finance). Literasi keuangan akan mendorong financial knowledge seseorang akan meningkat (Dewi \& Rochmawati, 2020). Pengetahuan keuangan atau financial literacy adalah tingkat pengetahuan atau pemahaman seseorang terhadap keuangan. Mahasiswa yang dibekali dengan pendidikan keuangan yang baik akan memiliki pengetahuan keuangan yaang baik pula. Adanya pendidikan keuangan keluarga yang baik dan diimbangi dengan pendidikan keuangan di perguruan tinggi akan mempengaruhi tingkat literasi mahasiswa yang pada akhirnya akan berpengaruh terhadap perilaku keuangan yang dilakukan oleh mahasiswa. Munculnya masalah keuangan bukan saja karena rendahnya tingkat pendapatan, namun juga bisa berasal dari kurangnya pengetahuan seseorang dalam mengelola keuangannya.

Literasi keuangan merupakan financial knowledge yang dimiliki seseorang untuk mencapai kesejahteraan (Lusardi, 2019; Dewi \& Rochma- 
wati, 2020; dan Lusardi \& Mitchell, 2013).

Kesadaran diri terhadap uang juga merupakan bagian yang cukup penting untuk menyelamatkan kita dari masalah masalah keuangan. Kesadaran diri terhadap keuangan juga berhubungan dengan pendidikan keuangan dan pengetahuan keuangan (financial literacy). Kesadaran keuangan merupakan kondisi dimana seseorang mulai sadar akan keuangan melalui pemahaman keuangan yang dia miliki, dan mulai melakukan pengelolaan uang untuk mengindari masalahmasalah keuangan. Pada penelitian sebelumnya, Nafisah (2020) memperoleh kesimpulan bahwa jika mahasiswa memiliki tingkat literasi yang baik maka akan mampu meningkatkan perilaku menabung mahasiswa. Selanjutnya ia juga menyimpulkan teman sebaya dapat mempengaruhi perilaku menabung, dimana teman sebaya merupakan pihak eksternal yang dapat berpengaruh terhadap perilaku menabung. Begitu juga kontrol diri yang baik, mahasiswa yang memiliki kontrol diri yang baik akan berpengaruh juga pada perilaku menabungnya, mereka dapat mengontrol perilaku diri sendiri agar tidak bersifat konsumtif sehingga dapat mengambil keputusan yang tepat dalam aktivitas keuangannya.

Sedangkan hasil penelitian Melmusi (2017) menunjukkan bahwa teman sebaya, literasi keuangan dan kesadaran keuangan yang didukung oleh penelitian Alekam et al. (2018). Berdasarkan beberapa faktor diatas, penelitian ini meneliti pengaruh faktor-faktor tersebut terhadap manajemen keuangan pribadi (personal finance) mahasiswa Fakultas Ekonomi di Yogyakarta. Hasil penelitian ini besar harapan peneliti agar nantinya mahasiswa dapat lebih peduli dan sadar akan pentingnya pengelolaan keuangan untuk menghindarkan diri dari masalah-masalah keuangan yang ada. Sehingga pada saat berkeluarga dan bermasyarakat nantinya mahasiswa menjadi lebih siap dan matang untuk meniti masa depan yang baik. Dengan begitu maka perokonomian keluarga kedepannya akan ikut meningkat kualitasnya berkat masyarakat yang lebih peduli dan sadar akan pentingnya pengelolaan keuangan (money management).

Penelitian ini berkaitan dengan perilaku keuangan. Tujuan penelitian untuk mengetahui pengaruh pendidikan keuangan di keluarga, pendidikan keuangan di kampus, teman sebaya, literasi keuangan dan kesadaran keuangan terhadap tingkat personal finance mahasiswa.

\section{PENGEMBANGAN HIPOTESIS}

Personal Finance adalah bentuk dari pengelolaan uang (money management) namun penerapannya dilakukan oleh individu dan untuk tujuan individu juga. Personal Finance tentang bagaimana cara kita mengatur keuangan, bagaimana pendapatan kita dapat dialokasikan dengan baik agar dapat memenuhi kebutuhan dan mewujudkan keinginan kita serta menyelamatkan kita dari masalah-masalah keuangan. Generasi muda saat ini berhadapan dengan tantangan yang dimana sumber pendapatan terbatas sedangkan biaya hidup makin tinggi (Dangol \& Maharjan, 2018). Oleh karena itu pengetahuan keuangan sangat penting untuk membantu generasi muda dalam membuat keputusan yang tepat dalam pengelolaan keuangannya. Setiap individu dan keluarga memiliki pengetahuan dan kemampuan yang berbeda dalam mengelola dan membuat keputusan atas harta kekayaannya seperti, mengelola aset, tabungan jangka pendek, tabungan hari tua, membeli hal yang diinginkan, dan untuk kebutuhan seharihari (Dangol \& Maharjan, 2018). Menurut Natalia et al. (2019) pengelolaan keuangan (personal finance) adalah teknik mengimbangi gaya hidup manusia seperti gaya hidup konsumtif dengan gaya hidup produktif seperti investasi, menabung ataupun bisnis. Tujuan pengelolaan keuangan ini adalah agar kita terhindar dari kondisi lebih banyak hutang daripada pemasukan.

Belajar adalah suatu sistem yang terdiri dari berbagai komponen yang saling berhubungan satu sama lain. Komponen itu termasuk tujuan, bahan, metode, dan evaluasi. Keempat komponen pembelajaran harus dipertimbangkan oleh guru dalam memilih dan menentukan media, metode, strategi, dan pendekatan yang digunakan dalam kegiatan pembelajaran (Susanti et al., 2019). Sari (2015) menyatakan bahwa pembelajaran keuangan di perguruan tinggi sebagai sarana penting bagi sumbangan pengetahuan literasi mahasiswa. Sedangkan teman sebaya adalah hubungan sosial yang terbentuk karena adanya tujuan pencarian jati diri yang dilakukan oleh dua orang atau lebih yang memiliki usia yang setara, serta kematangan yang sama, dimana mereka saling mengenal identitas sosial satu sama lain dan dapat mempengaruhi satu sama lain. Remaja sering menempatkan teman sebaya dalam posisi prioritas apabila dibandingkan dengan orang tua atau gurunya.

Literasi keuangan merupakan kebutuhan dasar yang dibutuhkan seseorang sehingga mereka dapat menghindari masalah keuangan. Menu- 
rut Darmawan et al. (2018) Literasi keuangan umum adalah literasi keuangan individu tentang pengetahuan keuangan dan aset keuangan yang ada. Financial literacy atau literasi keuangan memainkan peran penting bagi setiap orang dalam mengelola keuangan personal atau personal finance (Gunardi et al., 2017). Baik tidaknya pengelolaan keuangan pribadi ini erat kaitannya dengan kemampuan serta pengetahuan seseorang akan konsep-konsep keuangan yang dikenal dengan literasi keuangan. Laily (2016) menyatakan bahwa literasi keuangan erat kaitannya dengan manajemen keuangan, dimana semakin tinggi tingkat literasi keuangan seseorang, maka makin baik juga manajemen keuangan seseorang tersebut, itu berarti bahwa literasi keuangan berperan cukup penting dalam mempengaruhi manajemen keuangan pribadi (personal finance). Menurut Peeters et al. (2018) untuk mengembangkan perencanaan keuangan atau perancangan keuangan dibutuhkan kesadaran keuangan atau minimal pengetahuan keuangan (financial literacy). Alekam et al. (2018) meneyatakan bahwa berada dalam lingkungan sosial yang berpendidikan keuangan akan meningkatkan kesadaran individu untuk mengelola keuangannya dan lebih baik dalam membuat keputusan keuangan. Sehingga dapat dirumuskan hipotesis penelitian sebagai berikut:

$\mathrm{H}_{1}$ : Pendidikan keuangan di keluarga berpengaruh positif terhadap pengelolaan keuangan pribadi (personal finance)

$\mathrm{H}_{2}$ : Pendidikan keuangan di kampus berpengaruh positif terhadap pengelolaan keuangan pribadi (personal finance)

$\mathrm{H}_{3}$ : Teman sebaya berpengaruh positif terhadap pengelolaan keuangan pribadi (personal finance)

$\mathrm{H}_{4}$ : Literasi Keuangan berpengaruh positif terhadap pengelolaan keuangan pribadi (personal finance)

$\mathrm{H}_{5}$ : Kesadaran Keuangan berpengaruh positif terhadap pengelolaan keuangan pribadi (personal finance)

\section{DATA DAN METODE}

Penelitian ini merupakan penelitiankuantitatif yang bertujuan mencari hubungan dan menjelaskan sebab-sebab perubahan dalam fakta-fakta sosial yang terukur. Teknik pengambilan sampel menggunakan teknik non probability sampling yaitu teknik pengambilan sampel yang tidak memberikan peluang atau kesempatan yang sama bagi setiap anggota populasi untuk dipilih menjadi sampel. Teknik sampling menggunakan sampling incidental yaitu teknik penentuan sampel berdasarkan kebetulan. Serta peneliti menggunakan metode purposive sampling yaitu teknik penentuan sampel dengan pertimbangan tertentu. Pada penelitian ini pertimbangan-pertimbangan tersebut adalah: Mahasiswa Fakultas Ekonomi di Yogyakarta yang pernahmengambil mata kuliah Manajemen Keuangan dan Mahasiswa Fakultas Ekonomi di Yogyakarta yang pernah mengambil mata kuliah yang berkonsentrasi Keuangan. Teknik analisis data menggunakan analisis regresi berganda. Operasionalisasi variable disajikan pada tabel 1.

Tabel 1. Operasionalisasi Variabel Penelitian

\begin{tabular}{|c|c|}
\hline Variabel & Indikator \\
\hline $\begin{array}{l}\text { Pendidikan Keu- } \\
\text { angan di Keluar- } \\
\text { ga }\left(X_{1}\right)\end{array}$ & $\begin{array}{l}\text { a. Cara orang tua mendidik } \\
\text { b. Jumlah anggota keluarga } \\
\text { c. Pola belanja kebutuhan keluarga } \\
\text { d.Pengelolaan aset keluarga }\end{array}$ \\
\hline $\begin{array}{l}\text { Pendidikan Keu- } \\
\text { angan di Kampus } \\
\left(X_{2}\right)\end{array}$ & $\begin{array}{l}\text { a. Lingkungan tempat belajar } \\
\text { b. Cara pengajar menyampaikan } \\
\text { materi } \\
\text { c. Intensitas belajar Kegiatan } \\
\text { diluar kelas }\end{array}$ \\
\hline $\begin{array}{l}\text { Teman Sebaya } \\
\left(X_{3}\right)\end{array}$ & $\begin{array}{l}\text { a. Lingkungan pergaulan } \\
\text { b. Budaya pergaulan } \\
\text { c. Intensitas bertemu teman } \\
\text { Kekompakan dalam pergaulan }\end{array}$ \\
\hline $\begin{array}{l}\text { Literasi Keu- } \\
\text { angan / Financial } \\
\text { Literacy }\left(\mathrm{X}_{4}\right)\end{array}$ & $\begin{array}{l}\text { a. Pengetahuan mengenai } \\
\text { keuangan } \\
\text { b. Pengalaman keuangan } \\
\text { c. Latar belakang keluarga } \\
\text { d. Tempat pendidikan }\end{array}$ \\
\hline $\begin{array}{l}\text { Kesadaran Keu- } \\
\text { angan / Financial } \\
\text { Awareness }\left(X_{5}\right)\end{array}$ & $\begin{array}{l}\text { a. Gaya hidup } \\
\text { b. Tingkat kekayaan } \\
\text { c. Kejadian sekitar } \\
\text { d. Kemauan meningkatkan } \\
\quad \text { kualitas hidup }\end{array}$ \\
\hline $\begin{array}{l}\text { Manajemen Keu- } \\
\text { angan Pribadi / } \\
\text { Personal Finance } \\
\text { (Y) }\end{array}$ & $\begin{array}{l}\text { a. Keamanan keuangan } \\
\text { b. Kesehatan kekayaan } \\
\text { c. Penimbangan prioritas } \\
\text { kebutuhan } \\
\text { d. Kemampuan menabung } \\
\text { Kemampuan berinvestasi }\end{array}$ \\
\hline
\end{tabular}

Kuesiner telah dilakukan pengujian validitas dan reabilitas sebelum disebarkan ke responden. Hasil pengujian kuesiner menunjukkan semua indikator yang digunakan realibel dan valid.

\section{HASIL}

Hasil regresi untuk mengetahui pengaruh pendidikan keluarga, pendidikan kampus, temen sebaya, literasi keuangan dan kesadaran keuangan terhadap personal finance disajikan pada 
tabel 2. Hasil penelitian menunjukkan bahwa pendidikan keluarga, kesadaran keuangan dan literasi keuangan berpengaruh terhadap manajemen keuangan pribadi. Sedangkan pendidikan di kampus dan teman sebaya tidak berpengaruh pada tingkat signifikansi.

\begin{tabular}{|c|c|c|c|c|}
\hline \multirow[t]{2}{*}{ Model } & $\begin{array}{l}\text { Unstan } \\
\text { Coeff }\end{array}$ & \multicolumn{2}{|c|}{ Unstandardized } & Prob. \\
\hline & koef. & SE & & \\
\hline (Constant) & $-0,181$ & 0,532 & & 0,735 \\
\hline Pendidikan Keluarga & 0,260 & 0,075 & $-0,340$ & $0,001^{*}$ \\
\hline Pendidikan Kampus & $-0,28$ & 0,100 & 3,478 & $0,782^{*}$ \\
\hline Teman Sebaya & 0,111 & 0,084 & $-0,278$ & $0,190^{*}$ \\
\hline Literasi Keuangan & 0,223 & 0,113 & 1,970 & $0,052^{* *}$ \\
\hline Kesadaran Keuangan & 0,433 & 0,099 & 4,357 & $0,000^{*}$ \\
\hline $\mathrm{R}$ & 0,648 & & & \\
\hline $\mathrm{R}^{2}$ & 0,420 & & & \\
\hline$R^{2}$ adj & 0,390 & & & \\
\hline
\end{tabular}

\section{PEMBAHASAN}

\section{Pendidikan Keuangan di Keluarga Terhadap Personal Finance}

Hasil penelitian menunjukkan bahwa pendidikan keuangan di keluarga berpengaruh positif terhadap pengelolaan keuangan pribadi. Artinya bahwa pendidikan keuangan keluarga berpengaruh signifikan terhadap personal finance. Pendidikan keuangan keluarga berpengaruh terhadap manajemen keuangan pribadi (personal finance) pada mahasiswa fakultas ekonomi di Yogyakarta. Menurut Jamal et al. (2015) lingkungan sosial keluarga yang baik akan sangat mendukung kesuksesan hidup mahasiswa di kemudian hari. Ketika orang tua menunjukkan kebiasaan mengelola keuangan dengan baik maka hal tersebut juga akan dicontoh oleh anaknya, akan menjadi perilaku dan kebiasaan baik yang akan diterapkan oleh anaknya di kemudian hari. Dengan contoh secara langsung tentang bagaimana pengelolaan keuangan dalam keluarga oleh orang tua, hal tersebut akan masuk dalam pikiran bawah sadar mahasiswa dan pada akhirnya akan berpe-ngaruh terhadap perilaku keuangan mahasiswa.

\section{Pendidikan Keuangan di Kampus Terhadap Per- sonal Finance}

Hasil penelitian menunjukkan bahwa pendidikan keuangan di kampus tidak berpengaruh terhadap manajemen keuangan priba-di (personal finance) pada mahasiswa fakultas ekonomi di Yogyakarta. Tidak berpengaruhnya pendidikan keuangan di kampus terhadap personal finance disebabkan karena dalam mata kuliah keuangan di perguruan tinggi yang membahas mengenai keuangan perusahaan dan tidak berkaitan dengan manajemen keuangan pribadi (personal finance). Hal ini dapat menjadisaran bagi perguruan tinggi untuk lebihmemperhatikan literasi keuangan mahasiswa terkait dengan personal finance, dengan begitu secara tidak langsung perguruan tinggi juga turut berkontribusi dalam meningkatkan perekonomian negara, karena jika setiap individu memiliki personal finance yang baik maka masalah keuangan yang ada dapat ditanggulangi dengan baik dan perekonomian negara akan lebih maju kedepannya. Menurut Sari (2015) pembelajaran ke-uangan diperguruan tinggi sebagai sarana penting bagi sumbangan pengetahuan literasi mahasiswa. Dalam aktivitasnya, perguruan tinggi memberikan mata kuliah, pelatihan, workshop/ seminar, serta forum diskusi kepada mahasiswa. Hal ini secara langsung dapat mempe-ngaruhi tingkat pengetahuan mahasiswa mengenai literasi keuangan yang mahasiswa dapat. Pembelajaran pada perguruan tinggi mengenai keuangan memberikan impact bagaimana mahasiswa menggunakan dana, mempertimbangkanbelanja, serta dalam melakukan keputusan keuangan lainnya.

\section{Teman Sebaya Terhadap Personal Finance}

Hasil penelitian menunjukkan bahwa teman sebaya tidak berpengauh signifikan terhadap personal finance pada mahasiswafakultas ekonomi di Yogyakarta. Tidak berpengaruhnya teman sebaya terhadap personal finance disebabkan karena kurangnya kebiasaan diskusi masalah-masalah manajemen keuangan di kalangan mahasiswa, selain itu ada kecenderungan perilaku individualistik para mahasiswa dalam aktivitas berbelanja. 


\section{Literasi Keuangan Terhadap Personal Finance}

Hasil penelitian menunjukkan Literasi keuangan berpengaruh signifikan terhadap personal finance pada mahasiswa fakultas ekonomi di Yogyakarta. Menurut Dwiastanti \& Hidayat (2016) literasi keuangan menunjukkan kecakapan individu dalam memanfaatkan sumber daya yang dimilikinya untuk mencapai danmeningkatkan kesejahteraan, literasi keuangan merupakan hal penting yang tidak bisa dipisahkan dalam proses mengelola keuangan. Literasi keuangan erat kaitannya dengan personal finance, dimana semakin tinggi tingkat literasi keuangan seseorang, maka makin baik jugapersonal finance orang tersebut.

\section{Kesadaran Keuangan Terhadap Personal Finance}

Hasil penelitian menunjukkan bahwa Kesadaran keuangan berpengaruh signifikan terhadap personal finance pada mahasiswa fakultas ekonomi di Yogyakarta. Alekam et al. (2018) menyatakan bahwa berada dalam lingkungan sosial yang berpendidikan keuangan akan meningkatkan kesadaran individu untuk mengelola keuangannya dan lebih baik dalam membuat keputusan keuangan. Kesadaran keuangan merupakan kondisi dimana seseorang mulai sadar akan keuangan melalui pemahaman keuangan yang dia miliki, dan mulai melakukan pengelolaan keuangan untuk mengindari masalah-masalah keuangan. Dengan adanya kesadaran keuangan pada individu maka finansial individu tersebut juga akan lebih terkelola dengan baik

\section{SIMPULAN DAN SARAN}

Berdasarkan hasil penelitian, dapat disimpulkan bahwa Pendidikan-Keuangan di keluarga, Literasi Keuangan dan Kesadaran Keuangan berpengaruh terhadap personal finance mahasiswa Fakultas Ekonomi di Yogyakarta. Sedangkan Pendidikan Keuangan di Kampus dan Teman Sebaya tidak berpengaruh terhadap personal finance mahasiswa Fakultas Ekonomi.

Penelitian ini masih memiliki keterbatasanketerbatasan seperti responden yang masih terbatas pada mahasiswa Fakultas Ekonomi di Yogyakarta sehingga penelitian ini memberikan beberapa saran penelitian bagi mahasiswa ataupun bagi peneliti selanjutnya Untuk perguruan tinggi hendaknya menambah aktivitas akademik yang dapat menambah literasi mahasiswa terkait personal finance dan dapat ditambahkan variabel lain yang lebih objektif seperti: pengalaman keuangan, financial behaviour, pola belanja, pola menabung, dan lain-lain serta menambah responden yang lebih luas.

\section{DAFTAR PUSTAKA}

Ahmad, Z., Simun, M., \& Masuod, M. S. (2014). Determinants of Financial Behaviours among Malaysians. Indonesian Capital Market Review, 2(2), 121-132. https://doi.org/10.21002/icmr.v2i2.3663

Alekam, J. M. E., Salleh, M. S. B. M., \& Mokhtar, S. S. bin M. (2018). The Effect of Family, Peer, Behavior, Saving and Spending Behavior on Financial Literacy among Young Generations. International Journal of Organizational Leadership, 7(3), 309-323. https://doi.org/10.33844/ijol.2018.60258

Amagir, A., Groot, W., Maassen van den Brink, H., \& Wilschut, A. (2018). A review of financial-literacy education programs for children and adolescents. Citizenship, Social and Economics Education, 17(1), 56-80. https://doi.org/10.1177/2047173417719555

Ameliawati, M., \& Setiyani, R. (2018). The Influence of Financial Attitude, Financial Socialization, and Financial Experience to Financial Management Behavior with Financial Literacy as the Mediation Variable. $\mathrm{KnE}$ Social Sciences, 3(10), 811. https://doi.org/10.18502/kss.v3i10.3174

Chuah, S. C., Kamaruddin, J. N., \& Singh, J. S. K. (2020). Factors affecting financial management behaviour among university students. Malaysian Journal of Consumer and Family Economics, 25, 154-174.

Dangol, J., \& Maharjan, S. (2018). Parental and Peer Influence on the Saving Behavior of the Youth. International Research Journal of Management Science, 3(1), 42-63. https://doi.org/10.3126/irjms.v3i0.28035

Darmawan, A., Suyoto, Widhiandono, H., Utami, N. H., Razak, A. A. Z. A., \& Ab Wahid, H. (2018). The Effect of Financial Literacy, Financial Experience, and Locus of Control Towards Financial Management Attitude and Family Investment Planning Behavior. Proceedings International Conference of Business, Accounting and Economic (ICBAE UMP 2018), April, 206-215.

Dewi, I. A. K., \& Rochmawati, R. (2020). Pengaruh Money Attitude Terhadap Perilaku Pengelolaan Keuangan Pribadi: Pengetahuan Dan Financial Self-Efficacy Sebagai Moderasi. Jurnal Pendidikan Ilmu Sosial, 30(2), 
123-134.

https://doi.org/10.23917/jpis.v30i2.10956

Dwiastanti, A., \& Hidayat, C. W. (2016). Literasi Keuangan Ibu Rumah Tangga dalam Membentuk Perilaku Keuangan Keluarga. SNA MK Seminar Nasional Akuntansi, Manajemen $\mathcal{E}$ Keuangan.

Erawati, N., \& Susanti. (2016). Pengaruh Literasi Keuangan, Pembelajaran Di Perguruan Tinggi, Dan Pengalaman Bekerja Terhadap Perilaku Keuangan Mahasiswa Fakultas Ekonomi Universitas Negeri Surabaya. Jurnal Pendidikan Akuntansi (JPAK), 5(1), 1-7.

Ergün, K. (2018). Financial literacy among university students: A study in eight European countries. International Journal of Consumer Studies, 42(1), 2-15. https://doi.org/10.1111/ijcs.12408

Fatimah, N., \& Susanti. (2018). Pengaruh Pembelajaran Akuntansi Keuangan, Literasi Keuangan, Dan Pendapatan Terhadap Perilaku Keuangan Mahasiswa Fakultas Ekonomi Universitas Muhammadiyah Gresik. Jurnal Pendidikan Akuntansi (JPAK), 6(1).

Goyal, K., \& Kumar, S. (2020). Financial literacy: A systematic review and bibliometric analysis. In International Journal of Consumer Studies (Vol. 45, Issue https://doi.org/10.1111/ijcs.12605

Gunardi, A., Ridwan, M., \& Sudarjah, G. M. (2017). the Effect of Gender on Financial Literacy. Jurnal Keuangan Dan Perbankan, 21(3), https://doi.org/10.29106/fesa.615866

Gunay, G., Boylu, A. A., \& Oğuz, A. (2015). Determinants of financial management behaviors of families. In Handbook of Research on Behavioral Finance and Investment Strategies: Decision Making in the Financial Industry (Issue May 2018). https:/ / doi.org/10.4018/978-1-4666-74844.ch014

Herdjiono, I., \& Damanik, L. A. (2016). Pengaruh Financial Attitude,Financial Knowledge, Parental Income Terhadap Financial Management Behavior. Jurnal Manajemen Teori Dan Terapan| Journal of Theory and Applied Management, 9(3), 226-241. https://doi.org/10.20473/jmtt.v9i3.3077

Hidayat, S. (2020). Literasi Keuangan Untuk Pengelolaan Keuangan Pribadi. Syariah (EKUITAS), 1(2), 130-133. https:/ / slideplayer.info/slide/1972619/
Idris, F. H., Krishnan, K. S. D., \& Azmi, N. (2013). Relationship between financial literacy and financial distress among youth in malaysia. Malaysian Journal of Society and Space 9, 4(4), 106-117.

Isomidinova, G., Singh, J., \& Singh, K. (2017). Determinants of financial literacy: a quantitative study among young students in Tashkent, Uzbekistan. Electronic Journal of Business \& Management, 2(1), 61-75.

Jamal, A. A. A., Ramlan, W. K., Karim, M. A., Mohidin, R., \& Osman, Z. (2015). The Effects of Social Influence and Financial Literacy on Savings Behavior: A Study on Students of Higher Learning Institutions in Kota Kinabalu, Sabah. International Journal of Business and Social Science, 6(111), 110-119.

Johnson, E., \& Sherraden, M. S. (2007). From Financial Literacy to Financial Capability Among Youth Center for Social Development. Journal of Sociology and Social Welfare, 34(3), 119-145. http://gwbweb.wustl.edu/csd

Laily, N. (2016). Pengaruh Literasi Keuangan Terhadap Perilaku Mahasiswa Dalam Mengelola Keuangan. Journal of Accounting and Business Education, 1(4). https://doi.org/10.26675/jabe.v1i4.6042

Lusardi, A. (2019). Financial literacy and the need for financial education: evidence and implications. Swiss Journal of Economics and Statistics, 155(1), 1-8. https://doi.org/10.1186/s41937-019-0027-5

Lusardi, A., \& Mitchell, O. S. (2013). The economic importance of financial literacy. NBER Working Paper No. 18952.

Malinda, M. (2017). Edukasi Perencanaan Keuangan Terhadap Perubahan Perilaku Mahasiswa Mengelola Keuangan. Forum Manajemen Indonesia, 1. http:/ / dx.doi.org/10.1016/j.encep.2012.03.0 01

Melmusi, Z. (2017). Faktor faktor yang mempengaruhi literasi finansial mahasiswa Fakultas Ekonomi (Studi kasus di Universitas Putra Indonesia "YPTK" Padang). Majalah Ilmiah, 24(2), 221-229.

Natalia, D. E., Murni, S., \& Untu, V. N. (2019). Analisis Tingkat Literasi Dan Pengelolaan Keuangan Pribadi Mahasiswa Di Fakultas Ekonomi Dan Bisnis Univeristas Sam Ratulangi. Jurnal EMBA: Jurnal Riset Ekonomi, Manajemen, Bisnis Dan Akuntansi, 7(2), 21312140. 
https://doi.org/10.35794/emba.v7i2.24018

Pahlevi, R. W., \& Oktaviani, I. I. (2018). Determinants of Individual Investor Behaviour in Stock Investment Decisions. AFRE (Accounting and Financial Review), 1(2), 53-61.

https://doi.org/10.26905/afr.v1i2.2427

Pathirannahalage, S., \& Abeyrathna, G. M. (2020). Factors Affecting To Personal Financial Management Behaviours of Government Employees In Sri Lanka. International Journal of Scientific and Research Publications (IJSRP), 10(05),

761-767. https://doi.org/10.29322/ijsrp.10.05.2020.p1 0188

Peeters, N., Rijk, K., Soetens, B., Storms, B., \& Hermans, K. (2018). A Systematic Literature Review to Identify Successful Elements for Financial Education and Counseling in Groups. Journal of Consumer Affairs, 52(2), 415-440. https://doi.org/10.1111/joca.12180

Pradiningtyas, T. E., \& Lukiastuti, F. (2019). Pengaruh Pengetahuan Keuangan dan Sikap Keuangan terhadap Locus of Control dan Perilaku Pengelolaan Keuangan Mahasiswa Ekonomi. Jurnal Minds: Manajemen Ide Dan Inspirasi, $6(1), \quad 96$. https://doi.org/10.24252/minds.v6i1.9274

Ramadhan, A. Y., \& Asandimitra, N. (2019). Determinants of Financial Management Behavior of Millennial Generation in Surabaya. Jurnal Minds: Manajemen Ide Dan Inspirasi, $\quad 6(2)$, 129-144. https://doi.org/10.24252/minds.v6i2.9506

Syuliswati, A. (2020). Pendidikan Pengelolaan Keuangan Keluarga, Gaya Hidup, Pembelajaran Serta Pengaruhnya Terhadap Literasi Keuangan. Akutansi Bisnis $\mathcal{E}$ Manajemen (ABM ), 27(1), 53. https://doi.org/10.35606/jabm.v27i1.553

Yushita, A. N. (2017). Pentingnya Literasi Keuangan Bagi Pengelolaan Keuangan Pribadi. Nominal, Barometer Riset Akuntansi Dan Manajemen, 6(1). https://doi.org/10.21831/nominal.v6i1.1433 0 